\title{
Antonio José Ponte: El Último CONTERTUlio
}

Guido Herzovich

Columbia University

Resumen: En La fiesta vigilada (2007), el escritor cubano (en el exilio) Antonio José Ponte ha rehabilitado un malestar en vías de desaparición para la mayor parte de Occidente: el temor de la cultura frente al Estado. Alrededor de él, Ponte ha escrito una notable elegía a la alta cultura, a la sensibilidad $y$ las operaciones en que se funda, incluso a la comunidad alternativa que parece ofrecer. A contrapelo de las lecturas "posmodernas" de Ponte, como la de Reinaldo Laddaga que aquí se discute, este artículo sugiere que a su atractivo no son ajenos el anacronismo y la melancolía, en tanto nos recuerda la época heroica de la autonomía literaria, tan desdibujada en tiempos de hegemonía del mercado.

Palabras clave: Antonio José Ponte-Literatura y Estado -Literatura y Mercado

\begin{abstract}
In La Fiesta Vigilada (2007), the Cuban writer-in-exile, Antonio José Ponte, resuscitates a theme in danger of extinction in much of the West: culture's fear in the face of the State. Around this issue, Ponte has written a noteworthy elegy to high culture, to its sensibilities and operations, and even to the alternative community which it purports to offer. Writing against the grain of "postmodern" readings of Ponte's work, such as that of Reinaldo Laddaga, this article suggests that Ponte's appeal is to some degree anachronistic and melancholic, insofar as he remind us of the grand era of literary autonomy, so faded in times of market hegemony.
\end{abstract}

Keywords: Antonio José PonteLiterature and the State-Literature and the Market 
"Gannon le refirió un chiste de gauchos entrerrianos. Están reunidos en el campo unos cuantos paisanos. Uno se levanta y dice: 'Señores, discúlpenme, voy a mear". Se retira; muy pronto vuelve sobre sus pasos y anuncia gravemente: 'Puede ser que también cague'. Borges comenta: 'A Gannon le gusta for the wrong reasons. Le gusta porque es sucio'. Se pregunta si el cuento le gustaría a Lugones, a Ricardo Rojas ("Contaba cuentos indecentes'), a Cicerón, a Aristóteles". Adolfo Bioy Casares, Borges (p. 1165)

En la mayor parte de Occidente no es ya el Estado, sino el mercado, la instancia que interpela a los sujetos a la entrada de la vida civil, ni es igualmente frente al Estado, sino dentro del mercado, que la literatura debe buscar su ubicación.

En un libro reciente, el escritor cubano (ahora en el exilio) Antonio José Ponte ha rehabilitado un malestar en vías de desaparición: el temor de la cultura frente al Estado. Menos que sobre el extinto debate entre capitalismo y comunismo, La fiesta vigilada (2007) nos habla de la subjetividad y la literatura en los tiempos del Estado, por lo tanto también sobre la figura del artista o el intelectual. Una ecuación similar que analizaremos brevemente se halla en La vida de los otros (2006), la película del alemán Florian Heckel von Donnersmark sobre la vigilancia cultural en Alemania del Este.

Este artículo se estructura como sigue. En la primera parte discuto la lectura que Reinaldo Laddaga hizo del libro; aunque su perspectiva es más bien excepcional en el panorama de la 
crítica sobre Ponte que suele exaltar en él, acaso con mayor justicia, valores más tradicionales ${ }^{1}$, revisar los procedimientos de La fiesta vigilada a contrapelo de la contemporaneidad radical que les adjudica Laddaga, permite mostrar en cambio la coherencia que los liga con la genealogía moderna de la que Ponte se vislumbra último heredero. A partir de esa articulación, en la segunda parte aprovecho dos películas, Roma, ciudad abierta y La vida de los otros, para investigar el problema central: cómo lo estético, al constituirse como una interpelación alternativa al Estado, permite postular una comu-nidad y en alguna medida una ética, que encuentran en la tertu-lia su sociabilidad imaginaria arquetípica ella también en vías de desaparición.

${ }^{1}$ Véase Teresa Basile (comp.), La vigilia cubana. Sobre Antonio José Ponte. 
"Los pedazos de la cabeza de Manuel de la Crur. permanecian dispersos mientras la policía se ocupaba del conductor culpable. Yo llevaba una maleta y tropecé con la nariz: La embestida del vebiculo habia conseguido rebanarla limpiamente y debía residir en ella el olfato de aquel viejo escritor, asi que procuré guardármela”.

(Ponte, 2007 p.94)

En un artículo del mismo año que el libro que discute, en su estilo panorámico, Reinaldo Laddaga (2007) consideró que "a partir de" La fiesta vigilada era posible reflexionar sobre el impacto de las nuevas tecnologías de la comunicación en la literatura de formato tradicional (editada en volúmenes, con nombre de autor), como un primer escalón para avizorar los desafíos que estas transformaciones depararán al hispanismo; ante todo, relativizar la importancia de las nociones de autor y obra.

Como es evidente, ese "a partir de" es tan tramposo como legítimo: Laddaga no parte de Ponte sino que llega a él, con sus intereses, sus reflexiones previas y su bibliografía. Aprovecha La fiesta vigilada encarnación "bella", nos dice para reseñar una serie de características compartidas por una serie de libros o autores, tan difundidas y consistentes que se trataría de un género en vías de canonización, tan común entre "escritores ambiciosos" como "la novela de tipo clásico" (Laddaga, 2007 p.333).

“La forma en cuestión es ésta: un escritor (alguien que en 
sus textos tematiza abiertamente el hecho de que es un escritor, que explicita en la narración que compone su fidelidad a un oficio ya antiguo, quizás anacrónico) relata memorias personales, historias que conoce, lecturas que ha hecho y fabulaciones que, en el curso del acto de narración que está en trance de desplegar, inventa; lo que, en los libros que encarnan esta forma, conduce de una memoria contada, de una lectura resumida, de una fabulación a la siguiente es, muchas veces, la mera asociación, de modo que los textos en cuestión se presentan como improvisaciones." (Laddaga, 2007 p.332)

W. G. Sebald, Orhan Pamuk, Joan Didion, Pierre Michon en aguas internacionales y Fernando Vallejo, Mario Bellatin, Segio Chejfec, Sergio Pitol, César Aira en el ámbito hispano serían, en algunos de sus libros, representantes de esta forma. No es casual, sin embargo, que elija ejemplificar con Ponte, que le permite este statement globalizante radical: "incluso Cuba".

Es que la argumentación de Laddaga es radicalmente global y "epocal". Componen sus referencias bibliográficas: una investigación sobre el individuo contemporáneo que Danilo Martucelli escribe para el caso francés y Laddaga extiende hasta donde llegue "la forma en cuestión"; un libro del sociólogo inglés John Thompson sobre el tipo particular de interacción que favorecen las nuevas tecnologías, de donde sale la noción de "intimidad mediada"; un artículo de Zygmunt Bauman sobre las artes en la "modernidad líquida".

El género del blog sobre todo pero también ciertos formatos de radio y televisión sería la eclosión de ese individuo en 
las tecnologías de comunicación actuales, produciendo "un cierto tipo de escena de enunciación" (p.333), a su vez en el origen de "la forma en cuestión". "No sé si Ponte está interesado en el hecho de los blogs escribe Laddaga, pero no me sorprendería si lo estuviera" (p.337).

Las reflexiones, aún las glosas de Laddaga me merecen genuino interés; pero me parecen muy dudosas en su pertinencia para el caso de Ponte. ¿Cómo soslayar que la de Ponte es una prosa radicalmente literaria: un texto trabajadísimo, o mejor: una prosa prolífica en tropos y recursos, con marcas enfáticas de acabamiento? La tempo-ralidad de esa prosa no es la del artista "contemporáneo" que se garantiza de antemano el desmantelamiento de la instala-ción, según nos informa Bauman. A diferencia de él y de "nosotros" Laddaga dixit, Ponte no aborrece "la permanen-cia" (p.340). Los títulos de sus otros libros ya lo revelan: son imágenes densas, plenas de resonancias; títulos largamente meditados, justos: Contrabando de sombras, Asiento en las ruinas, Las comidas profundas, El abrigo de aire. Todos tienen un momento contraintuitivo o, para decirlo con la palabra más literaria del siglo pasado, desautomatizador: hay que apearse y ponderar, es decir releer: ¿qué diversas posibilidades sintácticas me oculta? ¿y en qué direcciones sutiles me conduce? Si algo une a todos estos títulos que acabo de nombrar es la imposibi-lidad de encontrarles referente, lo cual los vuelve por default poéticos. Compárese por caso con Cómo me hice monja o Las noches de Flores, o cualquier otro de Aira: todos ellos, como sus frases, con su olor de tinta fresca.

Un segundo problema es el de la estructura. Según Laddaga, Ponte 
"ha compuesto un texto que se presenta menos como la clase de tejidos cerrados sobre sí que solían ser incluso las más vanguardistas de las novelas de la alta modernidad que como una serie de improvisaciones, en cada una de las cuales se compone un universo en un estado de relativa dispersión y cuyas partes el autor no pareciera sentirse obligado a anudar de manera particularmente apretada." (p.336)

Ciertamente La fiesta vigilada que muy dudosamente sea novela es menos anudada y más dispersa que En busca del tiempo perdido o la obra completa de Henry James, incluso tal vez que La Refalosa de Ascasubi, pero ni menos ni más que sugiero el Evaristo Carriego de Jorge Luis Borges. Tomo este ejemplo porque Ponte (lo dijo en una entrevista) no pasa dos o tres días sin pensar en Borges2, y porque me parece un libro "cuyas partes el autor no pareciera sentirse obligado a anudar de manera particularmente apretada" (p.336). Un caso ni treinta no niega una transformación epocal; pero en efecto este trabajo no pretende eso, sino mostrar la voluntad de Ponte de heredar una tradición literaria alta, moderna si se quiere, y la comparación puede acercarnos a sus procedimientos, para luego (en la segunda parte) investigar las categorías estéticas que los sostienen.

2 " ¿Y tus referentes en la literatura universal?", le preguntaron Mercedes Serna y Anna Solana. Ponte: "Supongo que Montaigne, Marcel Proust, Virginia Woolf, Borges. Quisiera no equivocarme. Borges habló de que no pasaba un día sin pensar en Chesterton. Y no es que yo no pase un día sin pensar en Borges, pero no pasan muchos días en que no piense en Borges, lea a Borges o recuerde una ocurrencia suya". (Serna, 2004) 
¿Qué anuda las cuestiones que Borges asocia vagamente con la vida y obra del poeta de Palermo? ¿Qué habilita la arbitrariedad de las inclusiones? Más, ¿qué garantiza su pertenencia, más allá de la indecidibilidad genérica, a la literatura? Ocurre que Borges es escritor; su prosa nos lo indica en cada frase. La certeza de esa pertenencia, sobre la que Piglia (1979) ha trabajado en términos de linaje, le permite prescindir de ciertas codificaciones de una manera que le estaba vedada, por ejemplo, a Roberto Arlt, cuyas pertenencia a la literatura se lee ante todo en la codificación genérica: sus novelas no podrían ser sino novelas; Arlt no puede darse el lujo de otra cosa.

Esto no quita que el tipo de montaje que efectúa Ponte -espacial, temporal, de soportes- sea muy distinto al de Borges, y quizás aquí Laddaga haga bien en leer ahí el impacto de la última tecnología. Pero uso la palabra montaje malintencionadamente, significando que habría que probar que esta yuxtaposición tiene algo de post respecto de la que no fue inusual en el XX sea en relación al cine o al zapping televisivo. "Ahora les cuento esta historia de la que hace poco me he enterado: éste es el ademán de la escritura. (...) Un paso más allá de este gesto están los blogs." (Laddaga, 2007 p.336)

Junto con la otra de la dispersión, me interesa discutir esta idea de la ilación bloguera aplicada a Ponte. Y para hacerlo de manera consistente intentaré mostrar la pretensión de autonomía del texto, es decir: la manera en que rige su relación con el mundo exterior, imponiendo exigencias y ofreciendo privilegios a los materiales que toma, y por lo tanto marcando un 
límite más o menos preciso que es -imagino- lo que referimos como cerrazón o autorreferencialidad en las obras modernas.

La exigencia: podríamos llamar en sentido amplio estetización al procedimiento de incorporación de materiales al régimen literario. Es decir: se debe operar alguna transformación sobre ellos para jerarquizarlos, y la manera más habitual es la genealogía - palabra que uso para referir la comparación del elemento nuevo con otro elemento que por alguna razón ya ha entrado en la tradición literaria.

Los ejemplos abundan en cada página. Van algunos, de distintos tipos3: 1. "Se asemejaba a Hélen Fourment, esposa de Rubens, en el caso de que el retrato del Louvre hubiese envejecido" (2005b p.92); 2. "La base de Lourdes desmantelada y el amontonamiento de desperdicios en las calles de La Habana cumplían una simultaneidad estricta. Como en un cuadro de Brueghel, concurrían el tiempo mítico y una temporalidad mucho más común” (p.146); 3. “. (...) el edificio parecía un préstamo de Gotham City" (p.147);; 4. "Ella se hace creer que el padre ha leído en los periódicos la noticia de su enlace, lo convierte en el Wakefield de Nathaniel Hawthorne" (2005b p.89); 5. "Un policía anterior a Bertillon emprendió la

\footnotetext{
${ }^{3}$ Las citas 1, 4 y 5 pertenecen a una sección inédita que figura en el manuscrito bajo el número 4 en el capítulo "Un paréntesis de ruinas" (Ponte, 2005b). El manuscrito -que fecho a partir a partir de la primera publicación de fragmentos del capítulo correspondiente en la revista Encuentro de la cultura cubana (Ponte, 2005a) - circula completo en Internet. La sección fue eliminada de la versión publicada por Anagrama (Ponte, 2007), a la que refieren las citas al texto salvo indicación contraria. La disponibilidad del manuscrito permitiría un análisis genético de los cambios, incluyendo la eliminación de esta sección particularmente densa en procedimientos de estetización, pero esto excede los objetivos de este artículo.
} 
búsqueda" (2005b p.89); 6. "Luego supe que todo el sueño era una variación sobre el tema del doble" (p.158).

Se asimila en cada caso: 1. algo real a otra cosa real ya figurada artísticamente; 2 . un juicio sobre lo real con uno sobre una obra; 3. algo real a algo ficcional, en este caso de la cultura popular; 4. una impresión de un tercero a algo ficcional que proyecta en su acervo; 5. algo real a otra cosa real pero que pertenece a la tradición letrada; 6. algo real con un tropo literario.

Si en términos generales el orden no parece del todo rígido -como argumenta Laddaga- es porque buena parte de los elementos apuntan a lo mismo, o se reenvían entre sí: es por eso que son más o menos intercambiables. Pero este es precisamente el derecho que obtiene cada fragmento o historia o imagen al ser incorporado al régimen literario: volverse alegoría. Sea el derrumbe de una casa con sus habitantes adentro; sea la familia de vecinos sumidos en la parálisis y el reproche mutuo; sea su abuela paterna aislándose después del accidente -todas estas pequeñas historias quieren decirnos algo esencial sobre Cuba.

$Y$ si no son propiamente alegorías, en el sentido de apuntar a una totalidad, sí son (o al menos pueden ser) metáfora de otra cosa: entran en el régimen de lectura plural que define la densidad de la literatura, de la que Ponte habla en la misma entrevista4. Bastantes páginas después de describir a la familia

\footnotetext{
4 “A García Márquez le reconozco una gran fluidez narrativa. Le reconozco una gran cantidad de motivos que se han desgastado con el tiempo. Pero es un escritor sin profundidad que no merece relecturas. Cuando lo vas a releer es como seda que vas a acariciar de nuevo y se te deshace en las manos. Muy poco denso García Márquez. Aunque quizás las Mil y una noches tampoco sean densas. Sin embargo, las Mil y una noches
} 
de vecinos, Ponte está refiriendo su vuelta de Portugal y su negativa al exilio: "Puede que diera un paso atrás por cortedad de imaginación o por cobardía. (Lo mismo que el hijo mayor de la familia de los bajos, volvía a cobijarme bajo la dictadura paterna después de haber probado algo de mundo)" (p.161-2).

Pero además no es cierto que la yuxtaposición sea tan azarosa. El recurso estructural más habitual de Ponte es precisamente la digresión que se revela símil: el fragmento escatológico sobre su abuela, por caso, es una metáfora expresionista para los "viejos escritores nacionales" de quienes él se construye único o incluso último heredero. La yuxtaposición y relación entre ambas (y el recurso se repite todo el tiempo, hasta volverse la forma privilegiada de significación) es necesaria y premeditada.

En términos de la definición, en el texto mismo, de una figura de autor -problema que le interesa a Laddaga-, el derecho de construir genealogías y (diríamos) el deber de producir metáforas son lo que determina una sensibilidad.

Podríamos definir esa sensibilidad en Ponte de diversas maneras. Una de ellas: como dispositivo retórico para hacer de la experiencia estética una forma de conocimiento. O como la capacidad de producir metáforas, o recurriendo a una idea antigua, de pensar mediante imágenes ${ }^{5}$ : un acceso intuitivo a la totalidad. A nivel textual, el ejercicio de la sensibilidad deja

eran cuentos de mercado, para contar en caravanas. Y estamos hablando de lo escrito" (Serna, 2004).

${ }^{5}$ La idea de que "el arte es el pensamiento por medio de imágenes" es la que Shklovski se proponía refutar en "El arte como artificio". Tzvetan Todorov (1991), Teoría de la literatura de los formalistas rusos. México: Siglo XXI, p.55. 
marcas; "signos", en sentido barthesiano. Caso paradigmático, verdadero tropo literario, es lo que llamaré estetización por vía meteorológica; un punto y aparte interrumpe la anécdota $y$ leemos "Fue en los meses de lluvia", o como en la escena de la expulsión de la Unión de Escritores: "Una mesa y cuatro sillas plásticas parecían haber caído en aquella terraza durante el aguacero. Las flores de un árbol cuyas ramas alcanzaríamos con sólo estirar los brazos cubrían las baldosas (...)" (p.40).

Si fue o no en los meses de lluvia, o si caían o no flores de un árbol mientras el Estado cubano retiraba a Ponte su carnet de escritor, es -podríamos argumentar- completamente irrelevante. Es por eso que son signos: porque nos dicen únicamente qué tipo de subjetividad, de experiencia de lo real tiene lugar allí. Capaz, en mitad de esa escena dramática, de medir la distancia que lo separa de las ramas, y no en metros sino en imaginarios brazos extendidos, Ponte nos hace saber que el verdadero escritor es socio vitalicio $-\mathrm{y}$ no de ninguna dependencia estatal, sino de la tertulia intemporal que es la escena moderna de pertenencia a la literatura. Ponte es escritor no tanto porque escribe sino porque tiene una subjetividad privilegiada (tal vez por eso experimenta una y otra vez el mundo como estando-ahí-para-él), de la misma manera que Rulfo es poeta (y García Márquez no) muy al margen de que componga versos ${ }^{6}$. Es pertinente aquí otro contraste didáctico.

\footnotetext{
6 "Ser poeta es el centro de toda mi vida literaria. (...) Pero más allá de mi caso personal, creo que un escritor, se dedique al género que sea, tiene una raíz poética. Al comparar Pedro Páramo y Cien años de soledad (vuelvo a lo anterior), se percibe que Rulfo tiene un misterio que no tiene García Márquez. No importa que Juan Rulfo no haya escrito un solo poema. No importa si era un lector habitual de poesía, la poesía estaba en su centro". (Serna, 2004).
} 
Aira suele decir: cada mañana voy al bar y escribo, primero una línea, después otra hasta que tengo una paginita diaria; y si llueve o cae una mosca en mi café, lo incorporo a lo que voy diciendo. Esta imagen mecánica, con su énfasis correspondiente en el procedimiento ${ }^{7}$, es lo opuesto a la figura de escritor de Ponte.

La meditación sobre las ruinas, tema predilecto de Ponte que se considera "ruinólogo", la sección "más bella" para Laddaga, pone en escena la tertulia que referíamos antes. Ponte ha contado su origen en Arte nuevo de hacer ruinas, un documental alemán que se sirve de su visión de La Habana: "Cuando empiezas a explicarte por qué me llaman tanto la atención las ruinas - ¿es perverso o no es perverso? - empiezas a buscar textos que te acompañen" (Borchmeyer, 2007, 26:00).

Para discurrir sobre las ruinas, forma que Laddaga encuentra también en vías de canonización, Ponte ha encontrado la compañía de Georg Simmel, María Zambrano, Victor Hugo, Mary Shelley, David Markson, Siegfried Giedion, Keats, Jean Cocteau, Kenneth Clark, John Piper, Victor Klemperer, W.G.Sebald, Marinetti, Christopher Woodward, Robert

\footnotetext{
${ }^{7}$ Aira vuelve regularmente a esta idea. Aquí una versión: "Ya se me ha vuelto un hábito aclarar que no escribo mucho sino poco, y hasta poquísimo. Nunca paso de una página por día, negociada muy lentamente y con toda clase de preparativos. (...) El surrealismo era algo muy vivo y estimulante en la Argentina de los años sesenta, los años de mi formación, que sucedió entre poetas. Todos mis amigos y maestros fueron poetas, incluidos de un modo u otro en la estela del surrealismo. De ellos tomé el procedimiento y los gestos. Nunca fui de esos novelistas que se sientan a la máquina de escribir y escriben en extenso. Lo mío fue, y sigue siendo, el dibujo laborioso de una escena, y al día siguiente otra, como los collages de Max Ernst o las cajas de Joseph Cornell” (Escobar Ulloa, 2004).
} 
Harbison, Graham Greene y el barón Haussmann -cediéndose la palabra unos a otros en pocas páginas.

Todos ellos -y otros más- llevan nombre completo. Pero el libro también abunda en letras mayúsculas, "D." o "B.", cuya referencia real es privilegio de los iniciados. Y está por último "el hijo mayor de la familia de los bajos" o compuestos similares, en verdad difíciles de citar. Son los límites de la comunidad lo que pone en juego en esas nomenclaturas. Su contracara es lo compartido, lo que posibilita el diálogo: tener o no tener la referencia, "el Wakefield de Nathaniel Hawthorne" o "igual a las llamas bajo los dulces prados del poema de Keats".

Así, también el lector puede medir su distancia o imaginarse nomenclado dentro de La fiesta vigilada. ¿Comparte el lector esa "memoria falsa" que se adjudica Ponte: esos "recuerdos de cuando no se estaba vivo"? En suma: la biblioteca que es requisito de un dispositivo "genealógico" de incorporación, y cuyo signo es la permanencia. A esa biblioteca Ponte ha legado infinitas cosas, las de su cosecha propia no menos que las ajenas que se ocupó de reavivar. Si Ponte no se sintiera el último de un linaje, y no temiera por la suerte de la herencia completa, no sería difícil imaginar que un tunecino del siglo XXIII, que se sintiera -como cierto argentino famosocon derecho a la tradición universal, escriba en su diario: "Esta mañana me han llamado de la gerencia; otra vez la misma humillación. Siempre me digo: ésta será la última -y a la mañana siguiente estoy ahí, como el hijo de la familia de los bajos de Ponte". 


\section{II}

“Tipejo miserable', me llamó el Ministro de Cultura, en reunión a la que no fui invitado".

(Ponte, 2007 p.47)

Dos películas, cuya pertinencia es evidente en grados diversos, serán igualmente útiles para pensar cómo las categorías estéticas de Ponte se articulan con una ética y con el Estado.

En la que narra su expulsión de la Unión de Escritores (p.40-50) Ponte ha reescrito una escena clásica, no por eso menos efectiva: la derrota material que es un triunfo ético. Frente al Estado que se describe en La fiesta vigilada no hay mayor mérito que la censura; y esos burócratas que lo declaran muerto para la vida civil, ipso facto lo declaran apto para la literatura.

Una encarnación famosa de esa escena clásica es la tortura y muerte de Manfredi, líder de la resistencia antifascista, en Roma, ciudad abierta de Roberto Rossellini. Se trata, primero que nada, de una escena de consumación: no sólo porque la película - fuera de una breve coda- termina ahí, sino porque recién al llegar a ese final dramático nos enteramos de que Manfredi no es un militante más, sino el líder. Y lo heroico de su gesta no se desprende de lo que hace -en la película sólo huye, y no sabemos casi qué ha hecho o qué hará- sino del encono que ha desatado en los oficiales nazis que ocupan el territorio. En esa escena de tortura es menos expresivo el cuerpo ensangrentado, a menudo fuera de cuadro, que la ansiedad creciente de los alemanes; el conflicto pasa a jugarse 
casi de inmediato en términos éticos: importa quebrarlo, no tanto conseguir información. Rossellini nos hace notar el amaneramiento y la perversidad -incluso sexual- de esos verdugos. "Podrán tocar su cuerpo, pero no han tocado su alma", murmura aproximadamente el cura que lo acompaña. Es así: Manfredi ha custodiado su silencio sin atisbo de debilidad alguno; luego escupe al general nazi, y enseguida muere. Perplejidad de los asesinos; algo se les escapa; se diría que no comprenden la virtud. De esa incomprensión se deriva un complejo de inferioridad, que transmutado en rencor mucho mejor que la diferencia política o filosófica entre comunismo y fascismo- nos explica la violencia.

En la reescritura de Ponte hay idéntico silencio frente a un Estado igualmente percibido como usurpador, es decir, igualmente incapaz de interpelar al sujeto: por eso fracasa el castigo. El protagonismo se lo llevan otra vez, aquí junto a las referencias meteorológicas, las maneras ruines -mediocres, hipócritas- de los burócratas, penosos avatares de la especie humana: "el ejemplar que tenía ante mí" (p.44), escribe Ponte. Menos que la perversidad se nos hace notar el anquilosamiento, y ante todo -esto es lo novedoso- el mal gusto: el "café azucaradísimo que hizo relamerse de gusto a mis interlocutores" (p.40) es previsible en estos malos escritores, admiradores de Lennon y los Beatles ("música de fiesta a la que tomar como música culta", p.43), carentes de profundidad artística ("centraban el conflicto de sus cuentos en la posibilidad o no de escuchar una balada de moda"). Ese mal gusto, nos informa Ponte, es una fijación adolescente ("seguían siendo esos mismos muchachos”, p.42), que elevado a cate- 
goría cultural engloba tanto a los Beatles como a Salinger, de quien se habla en estos términos en otra sección del libro. Pero la distancia estética -esto nos interesa- cifra también una diferencia ética:

"Andaban necesitados de candidez, eso era todo. Se autoinfligían credulidad, precisaban creer a pesar de las circunstancias. Confiaban en ilusionarse y los chicos de Liverpool ofrecían la música perfecta (...). Gracias a ella pudieron soportar las delaciones (si no delataron ellos), atravesaron las cacerías de brujas estudiantiles, consolaron sus penas propias y borraron los remordimientos frente a las de otros." (p.43-4)

Lo que revela ese mal gusto es la "infinita capacidad para el autoengaño" (p.230) que explica mejor que la maldad, según el historiador inglés Timothy Garton Ash -cuya investigación Ponte discute en el último capítulo-, las delaciones en la Alemania comunista.

Ética y estética se superponen también en la mejor película no hablada en inglés de 2006 -según los Oscars-, pertinente además porque intenta responder el mismo interrogante de Garton Ash que interesa a Ponte: ¿qué hizo de algunos delatores y de otros resistentes en la Alemania comunista?

La vida de los otros ofrece personajes de ambos grupos, cuya distinción estuvo a cargo en primera medida de la dirección de vestuario, y centra su conflicto en el tránsito de dos de ellos de un grupo al otro. La joven y bella (y suponemos que talentosa) actriz Christa-Maria Sieland sufre un exceso de vanidad, y por miedo a ver truncado su estrellato por la perversidad 
de un burócrata transige en acostarse con él; eventualmente incurre también en la delación de su novio, Georg Dreyman, dramaturgo cuyo talento otro burócrata describe con una hipérbole: el único de los fieles que es leído en el Oeste.

Tránsito opuesto hace el protagonista, Wiesler, el interrogador más experto e inescrupuloso de la policía secreta. Su transformación comienza cuando es asignado a espiar a Dreyman. Además de vestirse bien y tener una novia hermosa, el escritor posee una exuberante vida creativa y sexual, cosas que el espía sabe o descubre que carece, y enseguida empieza a averiguar que añora. Del rencor inicial, derivado de una insensibilidad estética explicitada al comienzo en la escena del teatro, a través quizás de un déficit de vanidad -origen de su compromiso sincero con la causa-, Wiesler se desliza hacia la empatía. Luego roba a Dreyman, y en plano cenital nos consta que lee, un libro de Brecht. A veces llora mientras escucha los dramas conyugales de los Dreyman por medio de auriculares. Luego salva al dramaturgo de las purgas. Luego -el muro ha caído; todos están todavía un poco traumatizados- el dramaturgo descubre la historia y le dedica una novela: "Sonata para un hombre bueno". ¿Cómo se comprende la bondad final del brutal interrogador? La respuesta nos acercará de vuelta a Ponte.

Al saber del suicidio de un amigo suyo, director de teatro proscripto, Dreyman va al piano y toca conmovido precisamente la "Sonata para un hombre bueno". En montaje paralelo vemos a Wiesler oyendo la pieza, el perfil derecho cubierto de lágrimas. Al terminar Dreyman le recuerda a su novia lo que Lenin habría dicho sobre Beethoven: "Si sigo escuchándolo, 
no acabaré nunca la revolución”. “¿Puede ser que alguien que haya escuchado esta música, alguien que la haya escuchado de verdad, quiero decir - se pregunta-, sea una mala persona?" La conversión de Wiesler tiene así dos caras inseparables: el despertar de la sensibilidad y su corrimiento respecto de la interpelación estatal, que hasta entonces había constituido su subjetividad.

Esta ligazón es tanto el tema de la película de Florian Heckel von Donnersmark como la clave para las meditadas glosas que hace Ponte de The File. A Personal History, el libro de 1997 donde Garton Ash "se preguntaba qué hacía de una persona un luchador de la resistencia y de otra un servidor fiel de la dictadura" en la Alemania comunista, la misma pregunta que se habría hecho antes sobre el nazismo. Espejándola respecto de Cuba (como nos deja claro en la visita final al "Museo del Ministerio del Interior" de La Habana), Ponte procede a repasar la "vasta antología de las debilidades humanas" (la frase es de Garton Ash) que ofrece el libro del investigador inglés.

Se trata de una media decena de historias de "delatores", puntuadas por condecoraciones estatales ("Medalla de Plata de la Patria al Valor", "medalla de bronce 'en señal de reconocimiento al servicio leal, honesto y escrupuloso realizado en el Ministerio de Seguridad del Estado"') y la verificación de relaciones "imaginarias" con el Estado. Por ejemplo:

"Llegó a creer que su trabajo policial constituía un canal directo de comunicación con las más altas esferas. 
Imaginaba cada informe suyo como pieza de influencia sobre los superiores, y bajo esta luz remitía a los poderosos recomendaciones de benevolencia. Si la policía secreta resume Ponte- había constituido un amigo epistolar para el profesor de literatura inglesa y un gestor empresarial para la directora de la galería de arte, ¿por qué no iba a ser lobby político, remedo de sociedad civil?” (p.228)

Siguen unos pocos encuentros con antiguos oficiales de la Stasi. Ponte escribe: "Envejecidos dentro de ropa deportiva de pésimo gusto, casi todos coincidían en una infancia difícil, en la desaparición de la figura paterna, y en haber tomado al cuerpo policial como sustituto del padre". (p.229)

Además de esta nueva referencia al mal gusto generalizado de los ex-oficiales, lo que Ponte subraya es el lugar central del Estado en la constitución subjetiva de estas personas. Todos creían tener una relación personal con él. Ponte (o acaso Garton Ash) los describe como personajes llenos de carencias, abrumados por pérdidas, aburridos en su anonimato. El Estado -para decirlo con Althusser- los había interpelado y ellos habían respondido "Soy yo": así habían entrado a la sociedad civil. Caso extremo, para los oficiales el Estado había sido un padre.

Ese Estado-padre aparece como una voz en otra escena alegórica de Ponte. Los altoparlantes de una fábrica vecina incitan a los trabajadores a producir más y mejor; la sección que lo consigue, además de la mención, obtiene el privilegio de elegir la música que escucharán todos.

La expulsión de Ponte de la Unión de Escritores, al igual que la tortura de Manfredi, funciona así como escena de 
consumación. Su silencio abstraído, signo de absoluta desidentificación respecto la autoridad que allí pretende (sin éxito) aplicar un castigo, viene a decir que su subjetividad se ha construido a espaldas del Estado, en otra esfera. Ponte desconoce -en sentido activo- al padre; convierte así la expulsión en fiesta de graduación. La voz en los altoparlantes no lo incita a producir más ni mejor, ni lo motiva el privilegio de elegir la música a cuyo ritmo producirán los otros. Pero así ha sido desde su infancia:

"Sin muerte en la familia por entonces, tropecé con mi primera corona fúnebre durante el acto de recordación de un mártir revolucionario. Calculo ahora cuán poco tiempo había transcurrido desde que lo mataran: diez años que entonces me parecían una enormidad porque iban más allá de mi edad cumplida. (...) Obligado a permanecer inmóvil mientras durase la guardia de honor, se me dormían los dedos de los pies y me dediqué a pensar que detrás de todo aquel acto, agazapadas tras arreglos de flores, estaban las hojas de la cyca que mi abuelo trasplantara." (Ponte, 2005b p.91)

El niño Ponte, a quien los discursos oficiales sólo le hacen dormir los dedos de los pies -tal vez por eso una de las estrategias de La fiesta vigilada es vaciar de discurso al ultradiscursivo Estado cubano-, ya vive, más intensamente por cierto, en el espacio de la sensibilidad.

Ese linaje ofrece una interpelación alternativa a la del Estado, y por lo tanto una pertenencia a otra comunidad. Y sin embargo, angustiosamente a lo largo del libro, Ponte vuelve a 
sentirse último heredero, "el único habitante de una ciudad de la que todos se habían largado" (p.150) ¿Pero cuál es esa ciudad en la que Ponte se ha quedado solo?

Que no se trata simplemente de La Habana lo indican las imágenes apocalípticas que Ponte glosa de dos novelas de muy diversa procedencia, The Last Man de Mary Shelley (1826) y Wittgenstein's Mistress de David Markson (1988), esta última "monólogo de una mujer convencida de ser la única persona viva en todo el mundo. Ella, lo mismo que el último hombre de Mary Shelley, recorría capitales europeas vacías, galerías de pintura donde pernoctaba y en las cuales quemaba cuadros para entrar en calor” (p.166). Ambos personajes, no menos legítimamente que Ponte, perciben el mundo como un "gran museo de ruinas" que está ahí-para-ellos.

La vida de los otros y La fiesta vigilada -que ya vinculó la reseña del libro que hizo El país (De la Nuez, 2007)- reavivan un temor de la cultura al Estado. Se diría -con la salvedad no menor de que para Ponte el Estado cubano no es un recuerdo- que reavivan tanto una idea de cultura como una idea de Estado que en la mayor parte del mundo occidental existen sólo como resabios.

En efecto, los Estados todavía espían; pero rara vez a los escritores. De su involucramiento en el debate estético, cuya historia es vasta y hasta curiosa -Stalin llamando por teléfono a los disidentes-, quedan los homenajes en los centenarios y poco más. Los ministros de Cultura, es imaginable, ya no llaman "tipejo" a los artistas, ni los enumeran de memoria para averiguar qué máquina de escribir tienen, como en cierta escena de La vida de los otros. Este mundo, para nosotros más fa- 
miliar, es el que intenta pensar Laddaga, pero difícilmente haga justicia ni a los conflictos ni a los procedimientos de La fiesta vigilada. ¿Podemos sin embargo dejarnos interpelar alegremente por la épica de "un escritor que intenta salvaguardar, en suma, la autonomía de la literatura en el seno de lo politico" (Zanín)?

En la película, cuando el dramaturgo Georg Dreyman corrige el texto que publicará en el Oeste para denunciar las traiciones del régimen comunista, el editor le reclama mayor legibilidad. Intransigente y asustado, Dreyman protesta: "iTiene que seguir siendo literatura, no un panfleto!". Es la escena arquetípica de constitución de la autonomía literaria: en el límite peligroso con la propaganda, que la contracara tanto del temor como de la seducción del Estado.

Bajo las condiciones de la modernidad -afirmó hace poco Boris Groys (2008)-, el arte se produce y llega al público o bien en forma de mercancía, o como instrumento de propaganda política; éste último, sin embargo, carece de toda legitimidad en las condiciones de la escena artística contemporánea. Lo cual no es sino un nuevo recordatorio de que la reivindicación autonómica es inseparable del estatuto mercantil, históricamente determinado, de la obra artística. ¿Por qué, en efecto, nos resulta tanto menos heroico que un escritor actual, fumando contra la ventana como Dreyman, pronuncie con igual temor: "iTiene que seguir siendo literatura, no mercancía!’? 


\section{Bibliografía}

\section{Corpus}

Borchmeyer, Florian (Director). (2007). Arte nuevo de hacer ruinas. Nueva York: Cinema Guild.

Henckel von Donnersmarck, Florian (Director). (2007). La vida de los otros. Culver City, Calif.: Sony Pictures Home Entertainment.

Ponte, Antonio José (2005a). "De 'Un paréntesis de ruinas'. Fragmentos de La fiesta vigilada". Encuentro de la cultura cubana 37/38 (verano/otoño): 111-25.

Ponte, Antonio José (2005b). La fiesta vigilada. Mimeo. https://www.scribd.com/doc/251183769/La-FiestaVigilada

Ponte, Antonio José (2007). La fiesta vigilada. Barcelona: Anagrama.

Roberto Rossellini (Director) (2005). Roma, ciudad abierta. London: Arrow Films.

\section{Textos críticos}

Basile, Teresa (comp.). (2009). Sobre La vigilia cubana. Antonio José Ponte. Rosario: Beatriz Viterbo Editora.

Bioy Casares, Adolfo. (2006). Borges. Barcelona: Destino.

De la Nuez, Iván. "La fiesta de los otros" (12/05/2007). El país.

http://www.elpais.com/articulo/narrativa/fiesta/otros/ elpepuculbab/20070512elpbabnar_15/Tes

Escobar Ulloa, Ernesto (2004). "Entrevista a César Aira". The Barcelona Review 44. http://www.barcelonareview.com/44/s ca.htm 
Groys, Boris (2008). Art Power. Cambridge, Massachusetts: MIT Press.

Laddaga, Reinaldo (2007). "La intimidad mediada. Apuntes a partir de un libro de Antonio José Ponte". Hispanic Review (autumn).

Piglia, Ricardo (1979). "Ideología y ficción en Borges". Punto de Vista, 2 (5). Buenos Aires.

Serna, Mercedes y Anna Solana (02/2004). "Entrevistan a Antonio José Ponte: No siento el peso de la tradición cubana". El otro mensual, 35. http:/ /www.eldigoras.com/eom03/2004/2/fuego35ajp 01.htm.

Zanín, Marcela (2009). "Presentación [de Teresa Basile (comp.), La vigilia cubana. Sobre Antonio José Ponte] leída en el VII Congreso Internacional Orbis Tertius. La Plata, Pasaje Dardo Rocha, 19 de mayo de 2009”. Orbis Tertius, 14 (15). La Plata. 